\title{
Rotundic acid enhances the impact of radiological toxicity on MCF-7 cells through the ATM/p53 pathway
}

\author{
ZHONG-FENG WANG ${ }^{1,2^{*}}$, WEN-YI SUN ${ }^{3 *}$, DE-HAI YU ${ }^{4}$, YAN ZHAO $^{5}$, \\ HONG-MEI XU ${ }^{6}$, YU-FANG HE ${ }^{7,8}$ and HAI-JUN LI ${ }^{1}$ \\ ${ }^{1}$ Department of Immunity, Institute of Translational Medicine and ${ }^{2}$ Department of Geriatrics, \\ The First Hospital of Jilin University, Changchun, Jilin 130021; ${ }^{3}$ Department of Clinical Pharmacy \\ and Pharmaceutical Management, School of Pharmaceutical Sciences in Jilin University, Changchun, \\ Jilin 130021; ${ }^{4}$ Cancer Center, The First Hospital of Jilin University, Changchun, Jilin 130021; \\ ${ }^{5}$ College of Chinese Medicinal Materials, Jilin Agriculture University, Changchun, Jilin 130000; \\ ${ }^{6}$ Department of Obstetrics, The First Hospital, Jilin University, Changchun, Jilin 130021; \\ ${ }^{7}$ Institute of Phytochemistry, Jilin Academy of Chinese Medicine Sciences, Changchun, Jilin 130000; \\ ${ }^{8}$ Changchun University of Chinese Medicine College of Management, Changchun, Jilin 130117, P.R. China
}

Received April 17, 2018; Accepted July 26, 2018

DOI: 10.3892/ijo.2018.4544

\begin{abstract}
Although radiation therapy is a powerful anticancer modality, radiation- induced stress response and gene expression with adaptive resistance may severely compromise the effectiveness of radiation. The function of rotundic acid (RA) on inducing apoptosis in the human breast cancer cell line MCF-7 has been investigated in a previous study. In the present study, the combined effect of chemotherapy and radiotherapy on reducing side effects was examined. The results of an MTT assay revealed that radiation $(0.5,2$ and $10 \mathrm{~Gy})$ effectively inhibit MCF-7 cell viability in a dose-dependent manner, consistent with the effects of RA $(2,5$ and $12.5 \mu \mathrm{M})$. Interestingly, a lower dose of radiation (1 Gy) combined with RA $(5 \mu \mathrm{M})$ exhibited a greater inhibition efficiency compared with a high dose of radiation alone. Flow cytometry revealed that radiation combined with RA induced the apoptosis of MCF-7 cells. Using western blotting, it was demonstrated that radiation induced the expression of ataxia-telangiectasia mutated (ATM) and p53 protein, and that RA enhanced this effect. On examining the potential underlying mechanism, it was revealed that radiation and RA combined induce $\mathrm{Bcl}-2$-associated $\mathrm{X}$ protein expression and cell apoptosis in MCF-7 cells. An ATM inhibitor was able to restore the effect of radiation and RA on inducing MCF-7 cell apoptosis. These results suggest that the ATM/p53 pathway directly
\end{abstract}

Correspondence to: Dr Hai-Jun Li, Department of Immunity, Institute of Translational Medicine, The First Hospital of Jilin University, 71 Xinmin Street, Changchun, Jilin 130021, P.R. China E-mail: hjli2012@jlu.edu.cn

*Contributed equally

Key words: rotundic acid, radiation, apoptosis, ataxia-telangiectasia mutated, tumor protein $\mathrm{p} 53$ participates in radiation and RA-induced apoptosis in MCF-7 cells. RA has the potential for development as a novel drug for the treatment of human breast cancer combined with radiation therapy, given that the combined side effects are reduced.

\section{Introduction}

Breast cancer is becoming an increasingly malignant cancer type with the highest morbidity rate globally, of which the onset age is decreasing (1). Each year, 1.2 million females are diagnosed with breast cancer globally, amongst which the majority succumb at 40-45 years old, however the onset age of the majority of patients is becoming younger (2). Over one-third of patients with breast cancer succumb to mortality from the disease (3). Radiation therapy may have a transformative impact on the treatment of breast cancer, as it allows women with an early stage of the disease to maintain the integrity of their body and those with advanced disease to have relief from suffering (4). Fisher et al (5) proved that breastconserving surgery with radiation has the same therapeutic effect as a mastectomy through a 20 -year randomized trial in 1,851 women with invasive breast tumor types. Although radiation therapy is a powerful anticancer modality, radiationinduced stress responses and gene expression alongside adaptive resistance may severely compromise the effectiveness of radiation (6). Mechanisms resulting in radiation therapy resistance are diverse and still poorly defined. One previous study has indicated that breast cancer stem cells develop resistance to radiation due to intrinsic and extrinsic mechanisms, genetic mutations and epigenetic modifications (7).

Traditional Chinese Medicine has had an impact on the tumor cell death pathway, which may guide tumor treatment decisions and clinical management (8). Nowadays, compounds derived from natural medicines with unique and diverse chemical entities still constitute a considerable resource for developing novel medicaments. Rotundic acid (RA) belongs 
to the pentacyclic triterpenoid family and is mainly identified in Ilex rotunda (I. rotunda), Ilex purpurea, Ilex integra and other Aquifoliaceae plants which are widely distributed in China (9). RA was also isolated from Mussaenda Pubescens and Guettarda platypoda of the Rubiaceae family $(10,11)$. Olea europaea and Planchonella duclitan, which are part of the Oleaceae and Sapotaceae families, respectively, also contain RA (12,13). Xu et al (14) demonstrated that RA, as one of a number of isolated compounds, demonstrated anticancer activity. Li et al (13) also reported that RA exerted cytotoxicity, with half maximal inhibitory concentration $\left(\mathrm{IC}_{50}\right)$ values of $9.5 \mu \mathrm{M}$, when it was applied on the MCF-7 cell line, but the exact mechanism underlying this effect remain unclear. Although RA exerted potential antitumor activity, its free carboxylic acid may result in problems when administered in vivo (15).

Radiation therapy is a standard treatment for local breast cancer. Adjuvant radiotherapy following breast conserving surgery may reduce the 10-year risk of first recurrence from 35.0 to $19.3 \%$ and 15 -year risk from 25.2 to $21.4 \%$ (16). However, high-dose and large-field radiotherapy may result in side effects including radiation dermatitis, lymphedema, lung toxicity, long-term cardiac toxicity and thyroid toxicity $(17,18)$. Chemotherapy and radiotherapy have effects on normal and tumor cells, which means patient have to suffer concurrent side effects, and the toxicity is dose-dependent (19-23). Therefore, identifying methods to reduce the dose of chemotherapy and radiotherapy, without affecting their therapeutic efficiency, is particularly important to tumor therapy. p53 serves a key role in the process of radiation response, controlling the activation of DNA repair and cell apoptosis pathways following acute radiation injury $(24,25)$. Therefore, novel therapeutic methods or novel antitumor methods for breast cancer may be identified by studying the p53 pathway (26). The results of combined effect of chemotherapy and radiotherapy will be beneficial for cancer therapy by reducing the side effects. As an important sensor, p53 may be a useful checkpoint for toxicity and radiation response. The present study was to investigate whether RA combined with radiotherapy exerts an effect on MCF-7 cells, which are a p53 gene wild-type cell line and are suitable for p53-dependent mechanism study. It may present as a potential antitumor drug combined with radiotherapy for the treatment of the breast cancer disease by reducing side effects.

\section{Materials and methods}

Reagents. RA (Fig. 1) was isolated and purified from I. rotunda, as reported in a previous study (27). Its purity was determined to be $\geq 98 \%$ using a high-performance liquid chromatography (HPLC) assay and the extraction yield of RA was up to $100 \mathrm{mg} / \mathrm{g}$. The HPLC system consisted of a Beckman 114 M solvent delivery module (Beckman Coulter, Inc., Brea, CA, USA), a Rheodyne syringe loading injector (model 9725) with a $100 \mu 1$ PEEK injection loop (Dionex Corporation, Sunnyvale, CA, USA), a Shimadzu ultraviolet spectrophotometric detector (UV VIS SPD-20A; Man-Tech Associates Inc., Guelph, ON, Canada), and a Hewlett-Packard HP3395 Integrator (Agilent Technologies, Inc., Santa Clara, CA, USA). Chromatographic separation was achieved on a $3 \mathrm{~mm} 110 \mathrm{~A}$ 150x3.0 mm i.d. C18 reversed phase analytical column oven at $35^{\circ} \mathrm{C}\left(\mathrm{Gemini}^{\circledR}-\mathrm{NX}\right.$; Phenomenex, Torrance, CA, USA) coupled with a $5 \mu \mathrm{m} 4.0 \times 3.0 \mathrm{~mm}$ i.d. C18 reversed phase guard column (Security ${ }^{\circledR}$ Guard Cartridges; Phenomenex) using a mobile phase consisting of a mixture of $0.005 \mathrm{M}$ potassium phosphate buffer at $\mathrm{pH} 7.2\left(\mathrm{KH}_{2} \mathrm{PO}_{4}\right)$ :acetonitrile:methanol (23:7:70). A total of $5 \mu \mathrm{l}$ sample was injected into the column every time. The flow rate used was $0.3 \mathrm{ml} / \mathrm{min}$.

MTT kit and RNase were purchased from Sigma-Aldrich (Merck KGaA, Darmstadt, Germany). The propidium iodide (PI) and Annexin V-fluorescein isothiocyanate (FITC) Apoptosis Detection kit was purchased from BD Biosciences (Franklin Lakes, NJ, USA). Dulbecco's modified Eagle's medium (DMEM), trypsin, fetal bovine serum (FBS), PBS, penicillin and streptomycin were obtained from Gibco (Thermo Fisher Scientific, Inc., Waltham, MA, USA). RA was dissolved in PBS ( $\mathrm{pH}$ 7.2) to prepare a stock solution at a concentration of $1.0 \mathrm{mM}$ which was stored at $-20^{\circ} \mathrm{C}$. DMEM complete medium was added to dilute the RA to the 2.0, 5.0 and $12.5 \mu \mathrm{M}$ prior to use.

Cell cultivation and treatments. Human breast cancer cell line MCF-7 was purchased from American Type Culture Collection (Manassas, VA, USA). Cells were maintained in DMEM supplemented with $10 \%$ FBS and $1 \%$ antibiotics. (penicillinstreptomycin). All cells were cultured at $37^{\circ} \mathrm{C}$ in a humidified incubator with a constant air flow of $5 \% \mathrm{CO}_{2}$. In order to inhibit the function of ataxia-telangiectasia mutated (ATM), $5 \mathrm{mM}$ caffeine (Sigma-Aldrich; Merck KGaA) dissolved in distilled water were added to the cell culture media 2 and $24 \mathrm{~h}$ prior to irradiation. Media containing this inhibitor were replaced with fresh medium immediately following irradiation.

Irradiation strategy. Monolayer cells were ionizing irradiated at the dose rate of $500 \mathrm{mGy} / \mathrm{min}$ using the X-RAD 320 X-Ray system (Precision X-Ray, North Branford, CT, USA). The total doses used were 0.5, 2.0 and 10.0 Gy. Subsequently, the cell culture media was replaced and cells were harvested immediately or continually cultured until the next step experiment was performed. Control groups were treated similarly but without irradiation.

Cell viability assay. The inhibitory effect of RA, irradiation or the two combined on the viability of MCF-7 cells were detected via MTT assays. All experiment steps were performed using cells seeded on 96 -well plates at a density of $5 \times 10^{4} / \mathrm{ml}$, and were performed according to the manufacturer's protocol (Sigma-Aldrich; Merck KGaA). Briefly, the cells were seeded at a density of $5 \times 10^{4} / \mathrm{ml}$ at a volume of $200 \mu \mathrm{l}$ per well. All groups without or with RA $(0.0,2.0,5.0$ and $12.5 \mu \mathrm{M})$ were incubated at $37^{\circ} \mathrm{C}$ for $24 \mathrm{~h}$. Irradiation treatment was completed $2 \mathrm{~h}$ prior RA administration. MTT reagent $(1.0 \mathrm{mg} / \mathrm{ml})$ was added to each well, and the cells were incubated at $37^{\circ} \mathrm{C}$ for $4 \mathrm{~h}$. The MTT solution was then aspirated, and $100 \mu \mathrm{l}$ dimethyl sulfoxide was then added. The 96-well plates were read using a microplate spectrophotometer (Synergy H1; BioTek Instruments, Inc., Winooski, VT, USA) at $540 \mathrm{~nm}$. The inhibition percentage was calculated as (1-the value of absorbance in the experimental group/the value of absorbance in the control group) $\times 100 \%$.

Flow cytometry for cell apoptosis. Annexin V-FITC and PI double staining flow cytometry analyses were employed to 
assess cell apoptosis. MCF-7 cells were plated in 96-well plates containing $200 \mu \mathrm{l}$ DMEM at a density of $5 \times 10^{4}$ cells/well. The induction of apoptosis in the MCF-7 cells were examined following treatment. The cell apoptosis was analysed using a flow cytometer (FACScan; BD Biosciences) with Flowjo 7.6 FACS analysis software (FlowJo LLC, Ashland, OR, USA). Briefly, the MCF-7 cells were washed with cold PBS then resuspended in $1 \mathrm{X}$ binding buffer [cat. no. 51-66121E; BD Biosciences; $0.1 \mathrm{M}$ HEPES/NaOH (pH 7.4), $1.4 \mathrm{M} \mathrm{NaCl}$ and $25 \mathrm{mM}$ $\left.\mathrm{CaCl}_{2}\right]$ at a density of $1 \times 10^{6}$ cells $/ \mathrm{ml}$. A total of $100 \mu \mathrm{l}$ solution ( $1 \times 10^{5}$ cells) was then transferred to a $5 \mathrm{ml}$ culture tube. Then, $5 \mu \mathrm{l}$ Annexin V-FITC (cat. no. 51-65874X; BD Biosciences) and $5 \mu \mathrm{l}$ PI (cat. no. 51-66211E; BD Biosciences) was added. The cells were gently vortexed and incubate for $15 \mathrm{~min}$ at room temperature $\left(25^{\circ} \mathrm{C}\right)$ in the dark. A total of $400 \mu 1 \mathrm{X}$ binding buffer was then added to each tube, and the cells were analysed using a flow cytometer within $1 \mathrm{~h}$. The cells in the different sections represented the different cell states as follows: Lateapoptotic cells were present in the upper right section, viable cells were present in the lower left section, and the early apoptotic were cells present in the lower right section.

Reverse transcription-quantitative polymerase chain reaction $(R T-q P C R)$. RT-qPCR was performed using ABI Plus one (Applied Biosystems; Thermo Fisher Scientific, Inc.) and the FastStart Universal SYBR Green Master (Roche Diagnostics $\mathrm{GmbH}$, Mannheim, Germany). Total RNA was isolated from the MCF-7 cells using a Qiagen RNAeasy kit (Qiagen, Inc., Valencia, CA, USA).cDNA was synthesized with Superscript II reverse transcriptase using random hexamer primers (Invitrogen; Thermo Fisher Scientific, Inc.) according to the manufacturer's protocol. The primers for p53, ATM and GAPDH were designed and synthesized by Sangon Biotech Co., Ltd. (Shanghai, China). An Applied Biosystems StepOne plus Fast Real-Time PCR system was used to determine the mRNA levels of p53, ATM and GAPDH (used as the internal control). The primer sequences for $\mathrm{p} 53$ were as follows: Sense, 5'-TTCCCACTGAGGAGTCCAAC-3' and antisense, 5'-TTGT TCCCGAAACGCTGAG-3'. The primer sequences for ATM were as follows: Sense, 5'-TTGCCTTGTATCTACTTTTG GGG-3' and antisense, 5'-TCAACACTGTTATGTTTGTG GGT-3'. The GAPDH primers were as follows: Sense, 5'-CCA GGTGGTCTCCTCTGACTT-3' and antisense, 5'-GTTGCTG TAGCCAAATTCGTTGT-3'. Amplification was performed for 40 cycles with a denaturation temperature of $94^{\circ} \mathrm{C}(5 \mathrm{sec})$, annealing temperature of $58^{\circ} \mathrm{C}(15 \mathrm{sec})$ and extension temperature of $74^{\circ} \mathrm{C}(10 \mathrm{sec})$ for $\mathrm{p} 53, \mathrm{ATM}$ and GAPDH in a thermal cycler (Veriti; Applied Biosystems; Thermo Fisher Scientific, Inc.). The PCR products were $200 \mathrm{bp}$ in length. Analysis of relative gene expression data was performed using the $2^{-\Delta \Delta \mathrm{Cq}}$ method (28).

Western blotting. Cell total protein was extracted using radioimmunoprecipitation buffer (Beyotime Institute of Biotechnology, Shanghai, China) supplemented with a cocktail protease inhibitor (Roche Molecular Diagnostics, Pleasanton, CA, USA), and the protein concentration was determined using a BCA protein assay kit (Beyotime Institute of Biotechnology) according to the manufacturer's protocol. A total of 5-40 $\mu \mathrm{g}$ cell total protein was separated by $10 \%$ SDS-PAGE and then

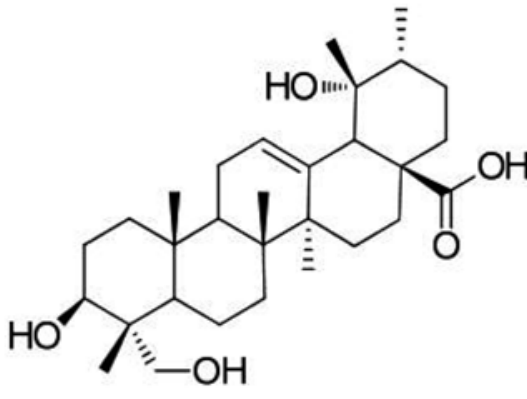

Figure 1. Structure of rotundic acid.

were electrophoretically transferred to polyvinylidene fluoride membranes (0.45 $\mu \mathrm{m}$; EMD Millipore, Billerica, MA, USA) and blocked at $37^{\circ} \mathrm{C}$ for $1 \mathrm{~h}$ with $5 \%$ skim milk in Trisbuffered saline (TBS) with Tween-20 (0.1\%). Subsequently, membranes were incubated with monoclonal antibodies against p53 (cat. no. 2254; 1:1,000), ATM (cat. no. 92356; 1:1,000), B-cell lymphoma 2 (Bcl-2; cat. no. 4223; 1:1,000), Bcl-2-associated X protein (Bax; cat. no. 2774; 1:1,000) and $\beta$-actin (cat. no. $3700 ; 1: 1,000$ ) at $4^{\circ} \mathrm{C}$ overnight. The primary antibodies used were all obtained from Cell Signaling Technology, Inc. (Danvers, MA, USA). Subsequent to washing 3 times for 5 min each with TBS, membranes were incubated with horseradish peroxidase-conjugated goat anti-mouse (cat. no. TA130001) or goat anti-rabbit (cat. no. TA130015) second antibodies (1:2,000; OriGene Technologies, Inc., Beijing, China) at $37^{\circ} \mathrm{C}$ for $1 \mathrm{~h}$. Subsequent to washing another 3 times, the immunocomplexes were detected using an enhanced chemiluminescence system (Thermo Fisher Scientific, Inc.) and X-ray film (Kodak, Rochester, NY, USA). Protein expression levels were determined semi-quantitatively by densitometric analysis with the Quantity One software (V4.62, Bio-Rad Laboratories, Inc., Hercules, CA, USA).

Statistical analysis. All data and results were calculated from at least three replicate measurements and presented as the mean \pm standard deviation. The differences between experimental groups and the control group were determined using a two-way analysis of variance followed by a Dunnett's t-test using SPSS version 20.0 (IBM Corp., Armonk, NY, USA). P<0.05 was considered to indicate a statistically significant difference.

\section{Results}

$R A$ and irradiation inhibit MCF-7 cell viability. The inhibitory effect of RA and irradiation on the viability of MCF-7 cells were detected via an MTT assay. The structure of RA is presented in Fig. 1. MTT detection revealed that RA significantly inhibited the viability of MCF-7 cells compared with the control cells $(\mathrm{P}<0.01)$. The inhibitory effects of RA on MCF-7 cells were dose-dependent within the ranges of 2.0-12.5 $\mu \mathrm{mol} / 1$. Treatment with RA at $12.5 \mu \mathrm{mol} / 1$ elicited the greatest inhibitory effect, with a cell viability of $41.3 \%$ compared with that of the blank control group (Fig. 2A; $\mathrm{P}<0.001)$. The irradiation experiment revealed that 0.5, 2.0 and 10.0 Gy doses of high dose irradiation (HDIR) significantly inhibited the growth of MCF-7 cells compared with the shamirradiated group (Fig. 2B; $\mathrm{P}<0.01$ ). Among them, the $10.0 \mathrm{~Gy}$ 
A

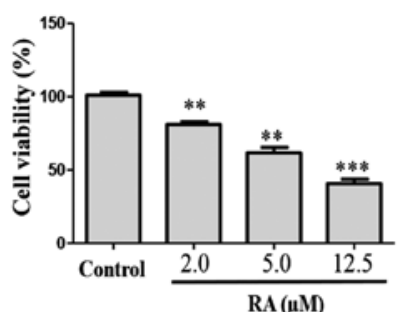

B

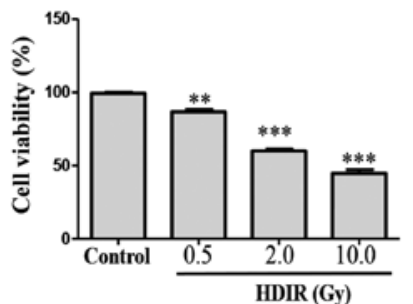

C

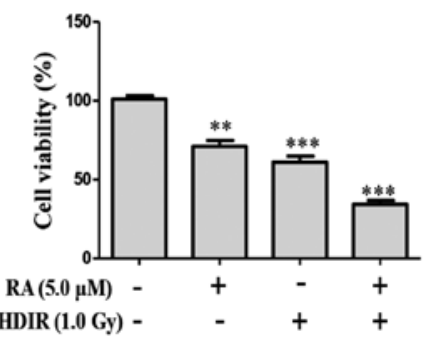

Figure 2. Cell viability of MCF-7 cells following treatment with different doses of RA and irradiation. MCF-7 cells were treated with varying doses of RA and irradiation for $24 \mathrm{~h}$. Cell viability was determined using MTT assays. (A) RA doses used were $2.0,5.0$ or $12.5 \mu \mathrm{M}$. (B) HDIR doses used were 0.5 , 2.0 or $10.0 \mathrm{~Gy}$. (C) Synergistic effect of RA and radiation combined on cell viability was assessed. RA dose used was $5 \mu \mathrm{M}$ and the irradiation dose used was $1 \mathrm{~Gy}$. The data are expressed as the mean \pm the standard deviation of three experiments. ${ }^{* *} \mathrm{P}<0.01$ and ${ }^{* * *} \mathrm{P}<0.001$ vs. control. RA, rotundic acid; HDIR, high dose irradiation.

irradiation had the most significant effect $(\mathrm{P}<0.001)$. In order to test whether RA exerted a combined effect with radiation on MCF-7 cells, low doses of RA ( $5 \mu \mathrm{M})$ and radiation (1 Gy) doses were used in combination. Suprisingly, RA combined with irradiation exerted a significantly greater inhibitory effect on MCF-7 cell proliferation compared with no RA or irradiation (Fig $2 \mathrm{C} ; \mathrm{P}<0.001$ ).

$R A$ and irradiation induce apoptosis in MCF-7 cells. To investigate whether RA and irradiation also induced MCF-7 cell apoptosis when combined, an Annexin V-FITC and PI double staining assay was performed. MCF-7 cells were treated with irradiation, RA or the two combined, and then analysed using flow cytometry. Fig. 3A and B indicate that compared with either treatment alone, the numbers of early and late apoptotic cells increased significantly in the RA and irradiation combined treatment groups $(\mathrm{P}<0.001)$. Treatment with RA at $5 \mu \mathrm{M}$ elicited a low apoptotic function $(21.3 \pm 2.6 \% ; \mathrm{P}<0.01)$, and treatment with irradiation at $1 \mathrm{~Gy}$ elicited a greater apoptosis function $(27.2 \pm 3.8 \%$; $\mathrm{P}<0.01)$. However, RA combined with irradiation groups elicited the greatest apoptotic capacity, which reached $51.2 \pm 4.5 \%$.

ATM/p53 pathway is involved in the effect of RA and irradiation combined in MCF-7 cell apoptosis. The present study further examined the expression of ATM and p53, which are also well
A

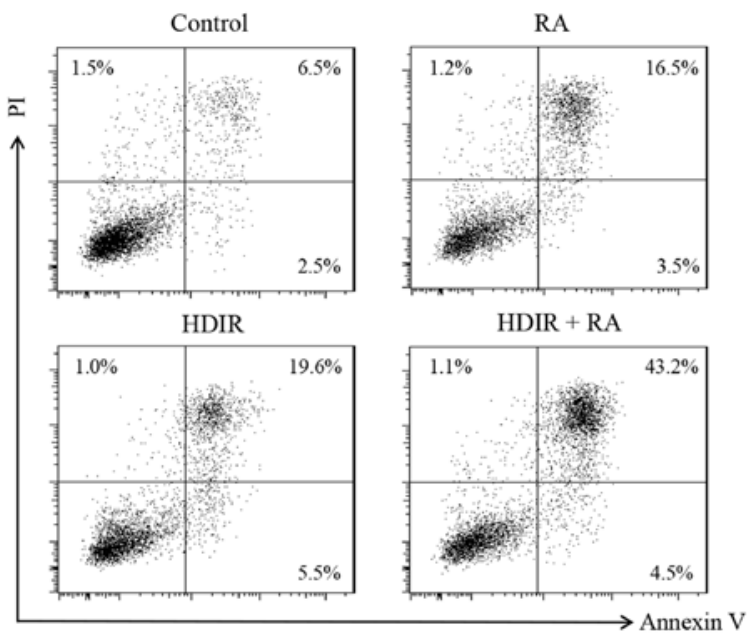

$\mathrm{B}$

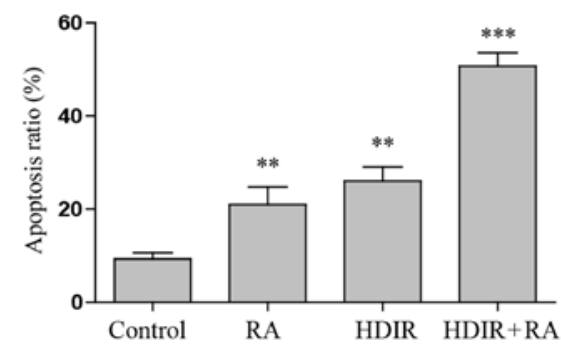

Figure 3. Detection of apoptosis by flow cytometry in MCF-7 cells treated with RA and HDIR. (A) Flow cytometric analysis of apoptosis in MCF-7 cells treated with RA $(1.0 \mu \mathrm{M})$ and HDIR (1 Gy). The cells were exposed to either control solution ( $0.1 \%$ dimethyl sulfoxide in medium) or treatment and incubated for $24 \mathrm{~h}$. (B) Percentage of apoptotic cells. The apoptotic cells were calculated as the percentage of apoptotic cells in the upper right section and the lower right section relative to the total number of the cells. The data are expressed as the mean \pm the standard deviation of three experiments. ${ }^{* *} \mathrm{P}<0.01$ and ${ }^{* * *} \mathrm{P}<0.001$ vs. control. RA, rotundic acid; HDIR, high dose irradiation; PI, propidium iodide.

known as critical DNA damage and radiation response sensors in mammalian cells (29). At $4 \mathrm{~h}$ post-irradiation, RA or the two treatments combined, the whole cell proteins of MCF-7 cells were extracted and separated by 4-8\% SDS-PAGE, and the expression of ATM and p53 were detected by western blotting. The expression of ATM and p53 in MCF-7 cells were revealed to be significantly upregulated by irradiation or RA treatment compared with the control $(\mathrm{P}<0.05)$, but the combined use of irradiation and RA exerted the most significant effect $(\mathrm{P}<0.001$; Fig. $4 \mathrm{~A}$ and $\mathrm{B})$. A RT-qPCR experiment confirmed that the gene expression of ATM and p53 were also significantly induced by RA and irradiation in Fig. 4C and D $(\mathrm{P}<0.01)$. Altogether, the results revealed that the ATM/p53 pathway serves a critical role in the effect of RA and irradiation combined on the apoptosis of MCF-7 cells.

$R A$ and irradiation activate the Bax/mitochondria cell apoptosis pathway in MCF-7 cells. Previously, antitumor mechanisms have mainly focused on their ability to trigger apoptosis. Apoptosis, known as programmed cell death, is closely associated with numerous anticancer reagents. When patients with cancer undergo chemotherapy, proapoptotic Bax may be upregulated in response to sensing DNA damage; and Bax in turn stimulates mitochondria to release cytochrome $c$. 
A

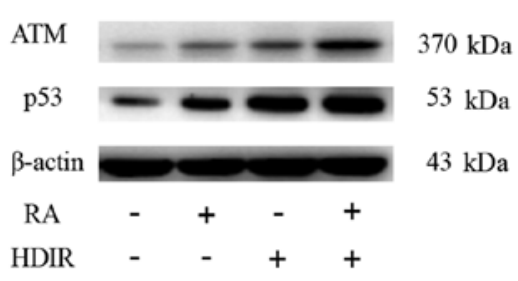

$\mathrm{C}$

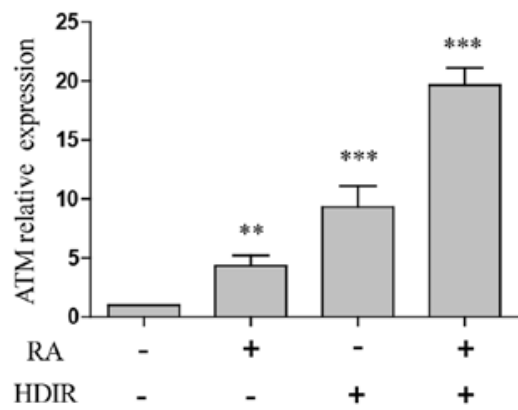

B

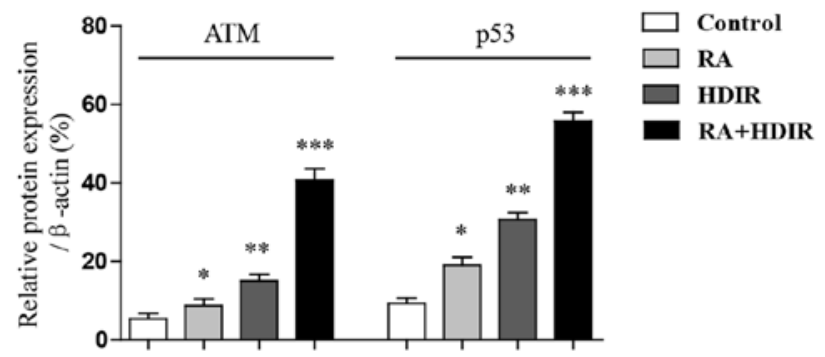

D

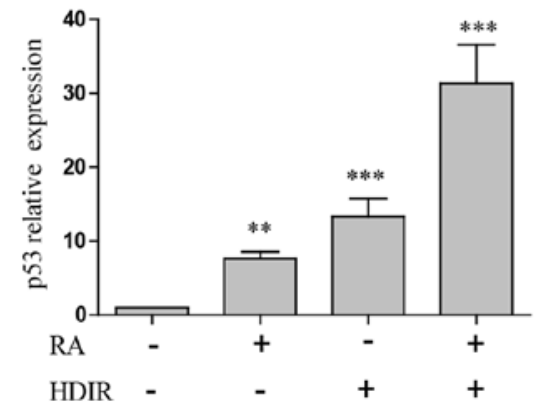

Figure 4. RA and HDIR induce ATM/p53 expression in MCF-7 cells. MCF-7 cells were treated with RA $(1.0 \mu \mathrm{M})$ and radiation $(1 \mathrm{~Gy})$ for $24 \mathrm{~h}$, and western blotting was used to assess the expression of ATM and p53 protein in MCF-7 cells. (A) ATM and p53 protein expression was detected by western blotting. (B) Quantitation of ATM and p53 levels. (C) Relative gene expression of ATM. (D) Relative gene expression of p53. The data are expressed as the mean \pm the standard deviation of three experiments. ${ }^{*} \mathrm{P}<0.05,{ }^{* * *} \mathrm{P}<0.01$ and ${ }^{* * * *} \mathrm{P}<0.001$ vs. control. ATM, ataxia-telangiectasia mutated; RA, rotundic acid; HDIR, high dose irradiation.

A

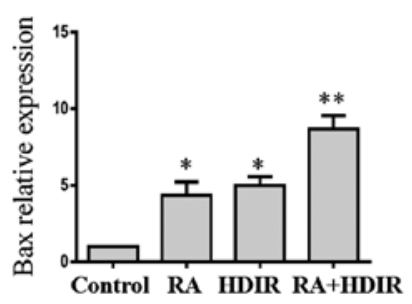

D

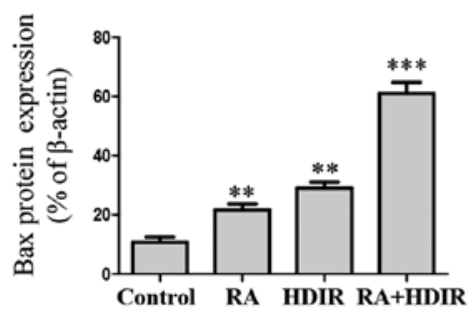

B

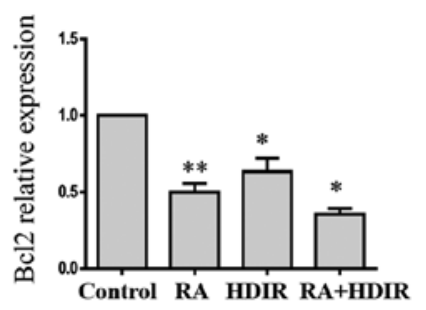

$\mathbf{E}$

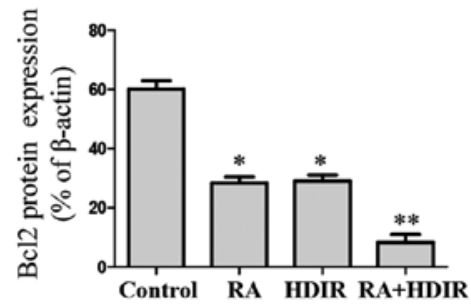

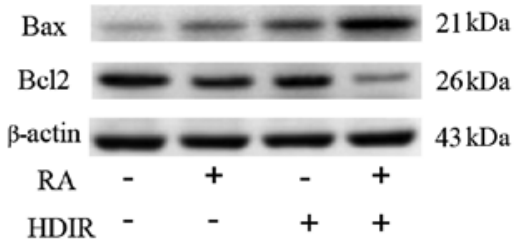

$\mathbf{F}$

Figure 5. RA and irradiation induce Bax expression and reduce $\mathrm{Bcl} 2$ expression in MCF-7 cells. MCF-7 cells were treated with RA (1.0 $\mu \mathrm{M})$ and HDIR (1 Gy) for $24 \mathrm{~h}$, and RT-qPCR and western blotting were used to assess the protein expression of Bax and Bcl-2 in MCF-7 cells. (A) Bax and (B) Bcl-2 gene expression was detected by RT-qPCR. (C) Bax and Bcl-2 protein expression was detected by western blotting. (D) Quantitation of Bax protein expression level. (E) Quantitation of Bcl-2 protein expression level. (F) The ratio of Bax/Bcl2. The data are expressed as the mean \pm the standard deviation of three experiments. ${ }^{*} \mathrm{P}<0.05,{ }^{* *} \mathrm{P}<0.01$ and ${ }^{* * *} \mathrm{P}<0.001$ vs. control. RA, rotundic acid; HDIR, high dose irradiation; Bcl-2, B-cell lymphoma 2; Bax, Bcl-2-associated $\mathrm{X}$ protein; RT-qPCR, reverse transcription-quantitative polymerase chain reaction.

Cytochrome $c$ is the major inducer of mitochondria apoptosis pathway (30). The protein expression of Bax and Bcl-2 were detected by western blotting. As presented in Fig. 5, RA and irradiation alone were able to significantly increase the gene (Fig. 5A; $\mathrm{P}<0.05$ ) and protein (Fig. 5C and D; $\mathrm{P}<0.01$ ) expression of Bax and significantly decrease the gene (Fig. 5B; $\mathrm{P}<0.05)$ and 
A

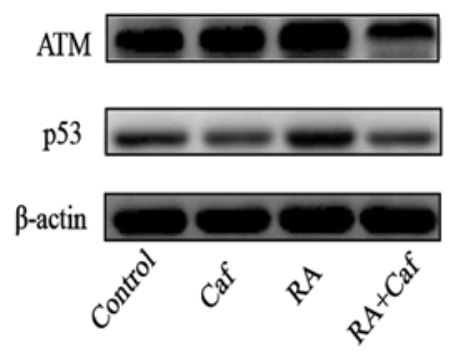

B

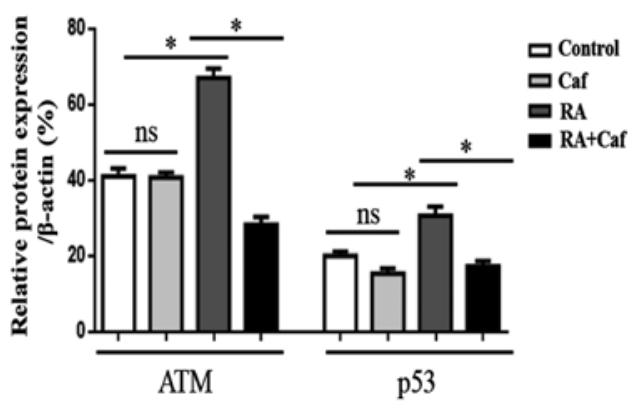

Figure 6. ATM inhibitor caffeine does not affect ATM expression, but inhibits p53 expression in MCF-7 cells. MCF-7 cells were treated with or without RA alone, caffeine alone or RA and caffeine combined. (A) The expression of ATM and p53 were measured by western blotting. (B) Quantitation of ATM and $\mathrm{p} 53$ protein expression level. The data are expressed as the mean \pm the standard deviation of three experiments. ${ }^{*} \mathrm{P}<0.05$ vs. control. ATM, ataxiatelangiectasia mutated; RA, rotundic acid; Caf, caffeine; NS, not significant. protein (Fig. 5C and E; P<0.05) expression of Bcl-2 compared with the control. The combined use of RA and irradiation amplified the effect further $(\mathrm{P}<0.05)$. The ratio of $\mathrm{Bax}$ to $\mathrm{Bcl}-2$ has been used in numerous studies $(31,32)$ in order to evaluate the level of apoptosis. In the present study, RA and irradiation combined significantly increased this ratio by elevating Bax expression and decreasing Bcl-2 expression in Fig. $5 \mathrm{~F}(\mathrm{P}<0.01)$.

ATM inhibitor restores $R A$ and irradiation-induced apoptosis in MCF-7 cells. To further address the function of the ATM pathway in RA and irradiation combined apoptosis induction in MCF-7 cells, caffeine was used to block the function of ATM. MCF-7 cells were treated without RA, caffeine or RA alone and RA and caffeine combined. The results revealed that caffeine does not affect ATM expression, but significantly inhibits 553 expression in MCF-7 cells compared with untreated cells $(\mathrm{P}<0.05$; Fig. $6 \mathrm{~A}$ and $\mathrm{B})$. Subsequent to the blocking of ATM with caffeine, the expression of ATM, $\mathrm{p} 53, \mathrm{Bax}$ and $\mathrm{Bcl}-2$ were measured by western blotting. It was revealed that the expression of ATM, p53 and Bax was decreased significantly but the Bcl-2 expression was increased significantly in cells treated with RA and irradiation combined in addition to caffeine compared with cells treated without caffeine (Fig. 7A and B; P<0.001). These results revealed that ATM is involved in mitochondrial apoptotic activity. Further apoptosis detection revealed that following treatment with
A

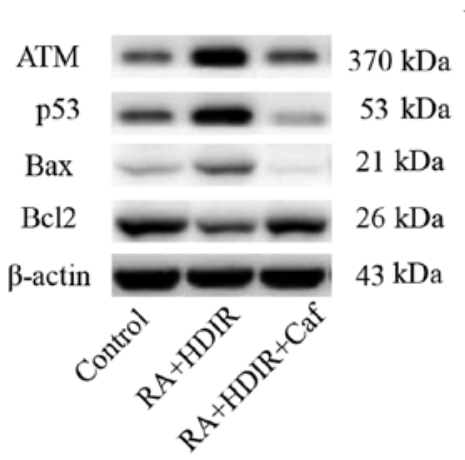

C

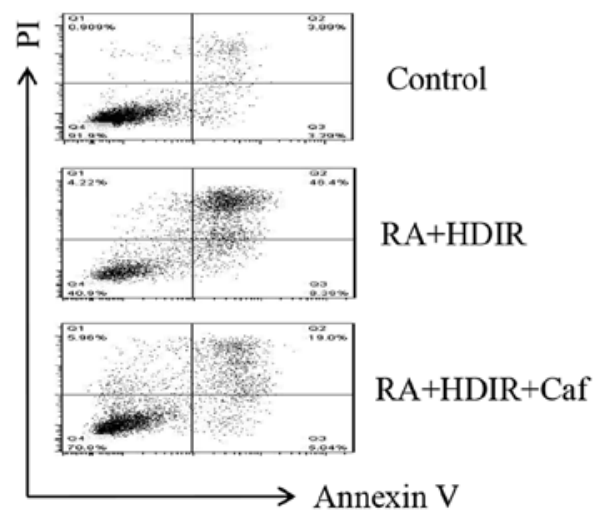

B

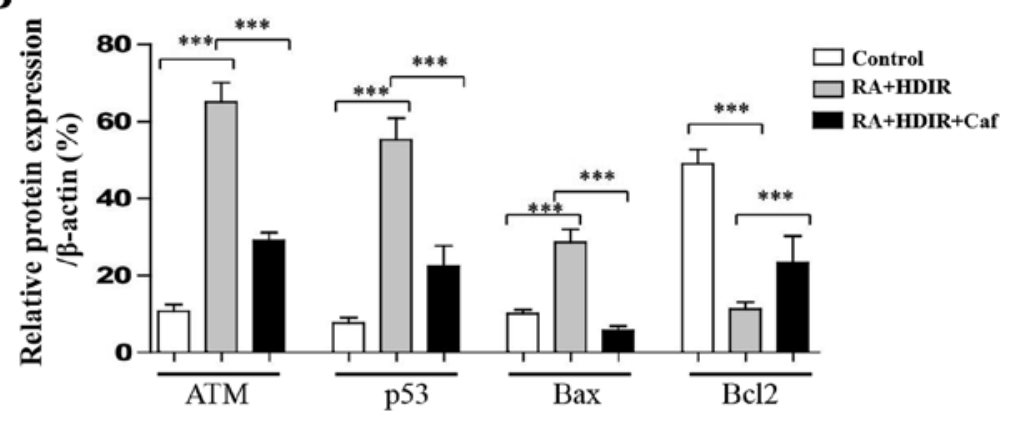

D

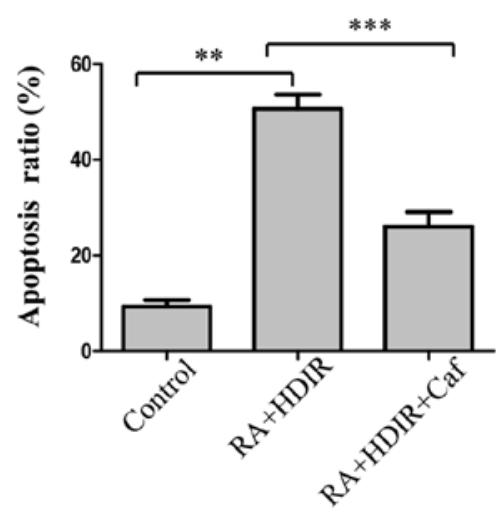

Figure 7. ATM inhibitor counteracts the RA and irradiation synergistical apoptosis induction in MCF-7 cells. MCF-7 cells were treated with RA (1.0 $\mu$ M) and HDIR (1 Gy) for $24 \mathrm{~h}$ subsequent to blocking with caffeine (an ATM inhibitor). (A) The protein expression of ATM, p53, Bax and Bcl-2 were measured by western blotting. (B) Quantitation of ATM, p53, Bax and Bcl-2 protein expression levels. (C) Flow cytometric analysis of apoptosis of MCF-7 cells. (D) Percentage of apoptotic cells. The data are expressed as the mean \pm the standard deviation of three experiments. ${ }^{* *} \mathrm{P}<0.01$ and ${ }^{* * *} \mathrm{P}<0.001$ vs. control. ATM, ataxia-telangiectasia mutated; Caf, caffeine; RA, rotundic acid; HDIR, high dose irradiation; Bcl-2, B-cell lymphoma 2; Bax, Bcl-2-associated X protein; PI, propidium iodide. 


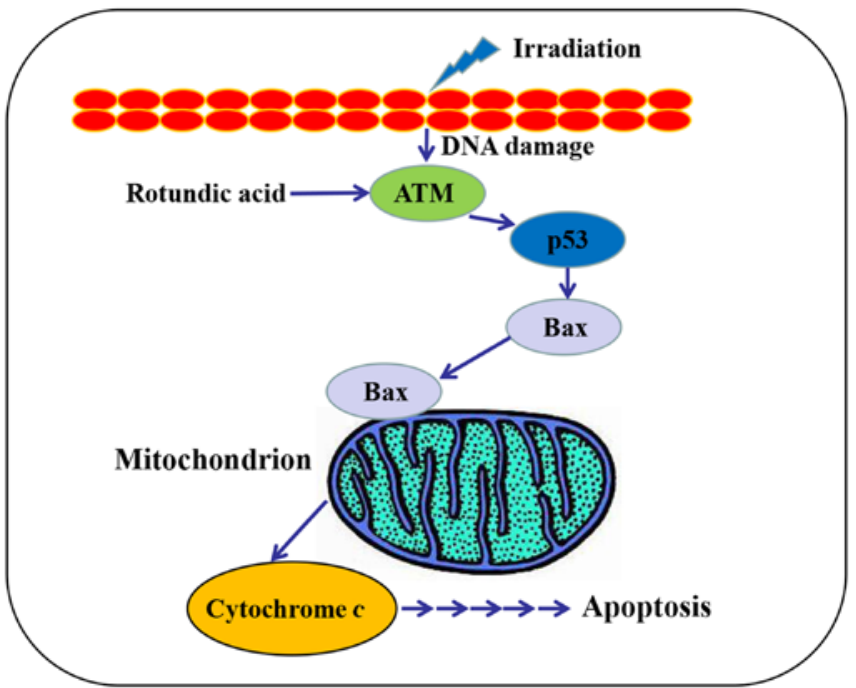

Figure 8. Schematic outline of the effect of rotundic acid in enhancing radiological toxicity in MCF-7 cell through the ATM/p53 pathway. Consistent with the experimental data, irradiation induced cell DNA damage and stimulated the ATM/p53 pathway. Rotundic acid may induce ATM expression synergistically. Proapoptotic Bax is upregulated in response to p53 activation, and Bax in turn stimulates mitochondria to release cytochrome $c$, which then initiates cell apoptosis. ATM, ataxia-telangiectasia mutated; Bax, Bcl-2-associated X protein.

caffeine, the viability inhibition in MCF-7 cells caused by RA and irradiation was abolished (Fig. $7 \mathrm{C}$ and D; $\mathrm{P}<0.001$ ). Together, these data suggest the involvement of the ATM/p53 pathway in the RA and irradiation combined-induced apoptosis of MCF-7 cells (Fig. 8).

\section{Discussion}

Breast cancer is a common malignant cancer globally and has threatened the health of women over the past few decades (33). There are a number of dangerous internal and external factors affecting the biology of tumor cells during the occurrence and progression of breast cancer (34). Oncogene disorder in the body has emerged as an increasingly important factor in the development of cancer. The metastasis and prognosis of breast cancer are associated with the mutation and abnormal expression of oncogenes (35). p53 is an important tumor suppressor gene and is present in the majority of normal cells, but is often mutated in cancer cells. One previous study revealed that the p53 gene mutation is associated with the resistance of breast cancer (36). Li et al (13) also reported that RA exerted cytotoxicity, with $\mathrm{IC}_{50}$ values of $9.5 \mu \mathrm{M}$ when it was applied to MCF-7 cells, but the exact underlying mechanisms remains unknown.

Although there are sufficient sources for the extraction of RA in China, as aforementioned, there remain few reports on its bioactivity due to little interest from pharmacological researchers. In an open patent, a substantial quantity of RA was isolated and purified from I. rotunda (37). Since RA may be a potential native anticancer drug with sufficient sources, a previous study has investigated and applied for a series of patents regarding RA and its derivatives during the past few years to investigate and make use of this compound (38). Radiation therapy is a standard treatment for local breast cancer. Adjuvant radiotherapy following breast conservation surgery may reduce the 10-year risk of first recurrence. However, highdose and large-field radiotherapy may result in side effects. Chemotherapy and radiotherapy have effects on normal and tumor cells, which means patient have to suffer concurrent side effects, and the toxicity is always dose-dependent (39). Therefore, identifying methods to reduce the dose of chemotherapy and radiotherapy, without affecting their therapeutic efficiency, is particularly important to tumor therapy (40). The present study aimed to investigate the combined effect of RA and radiotherapy, which may be beneficial for cancer therapy by reducing the side effects. Initially, the inhibitory effect of RA and irradiation on the viability of MCF-7 cells were detected via an MTT assay. MTT detection and flow cytometry revealed that RA significantly inhibited the viability of MCF-7 cells. The inhibitory effects of RA on MCF-7 cells were dosedependent within the ranges of 2.0-12.5 $\mu \mathrm{mol} / 1$. An irradiation experiment revealed that $0.5,2.0$ and 10.0 Gy doses of HDIR significantly inhibited the growth of MCF-7 cells compared with the sham-irradiated group. In order to assess whether RA exerts a combined function with radiation on MCF-7 cells, low doses of RA ( $5 \mu \mathrm{M})$ and radiation (1 Gy) were used. Surprisingly, RA combined with the irradiation demonstrated the greatest inhibitory effect on MCF-7 cell proliferation.

ATM is a crucial factor involved in the processing of DNA damage, maintenance of genome stability and control of cell cycle progression. According to Suzuki et al (41) phosphorylated ATM foci were detected immediately once normal human diploid cells were radiated. As a radiation sensor, the activation of ATM has been proved to be an early event of activated molecules and will interact with a number of cell signaling pathways, including the AKT and mitogen-activated protein kinase kinase/extracellular signal-regulated kinase pathways (42). p53 is a key factor in the process of radiation response, controlling the activation of DNA repair and cell apoptosis pathways subsequent to acute radiation injury (25). The present study further examined the expression of ATM and p53, which are also well known as critical DNA damage and radiation response sensors in mammalian cells. It was revealed that the expression of ATM and p53 in MCF-7 cells were upregulated by irradiation or RA treatment alone, but the combined use of irradiation and RA demonstrated substantially higher levels of ATM and p53. The ATM/p53 pathway serves a critical role in RA and irradiation-induced MCF-7 cell apoptosis. When a patient with cancer undergoes chemotherapy, proapoptotic Bax may be upregulated in response to sensing DNA damage. Bax in turn stimulates mitochondria to release cytochrome $c$. Cytochrome $c$ is the major inducer of mitochondria (30). The ratio of Bax to Bcl-2 has been used in numerous studies in order to evaluate the level of apoptosis $(43,44)$. The protein expression of Bax and Bcl-2 were detected in the present study. RA and irradiation alone may increase the expression of Bax and decrease Bcl-2 expression. The combined use of RA and irradiation amplifies this effect.

To further address the function of the ATM/p53 pathway in RA and irradiation-induced apoptosis in MCF-7 cells, caffeine was used to block the function of ATM. Subsequent to the blocking of ATM with caffeine, the expression of ATM was not decreased, but the expression of p53 and Bax decreased, and Bcl-2 expression was increased. These results demonstrated that ATM was involved in mitochondrial apoptotic activity. 
Cancer stem cells are a hot topic in current cancer research. Breast cancer stem cells display different proliferation and inhibition mechanisms to breast cancer cell lines. Future studies will examine the effects of RA and irradiation alone and combined on breast cancer stem cells, which will be more effective for understanding and curing breast cancer. In summary, the present study revealed that the $\mathrm{ATM} / \mathrm{p} 53$ pathway directly participates in the radiation and RA combined induction of MCF-7 cell apoptosis. RA has potential for development as a novel drug for the treatment of human breast cancer combined with radiation therapy, thereby reducing the concurrent side effects.

\section{Acknowledgements}

Not applicable.

\section{Funding}

The present study was supported by the Special Financial Grant from the China Postdoctoral Science Foundation (grant no. 2018T110251), the Jilin Provincial Natural Science Foundation of China (grant no. 20140520014JH to Dr Hai-Jun $\mathrm{Li}$; and grant no. 20180101135JC to Dr Hong-Mei Xu), the Interdisciplinary Chemistry and Medicine Foundation of Jilin University (grant no. JDYYJCHX004) and the National Natural Science Foundation of China (grant no. 31470418 to Y.H.).

\section{Availability of data and materials}

All data generated or analyzed during this study are included in this published article.

\section{Authors' contributions}

ZW and WS planed and performed the experiments, analyzed the data and wrote the manuscript. DY, YZ, HX and YH performed the experiments. HL designed, interpreted and funded the study, and wrote the manuscript.

\section{Ethics approval and consent to participate}

The present study was approved by the medical ethics committee of The First Hospital of Jilin University (Changchun, China).

\section{Patient consent for publication}

Not applicable.

\section{Competing interests}

The authors declare that they have no competing interests.

\section{References}

1. Metzger-Filho O, de Azambuja E, Bradbury I, Saini KS, Bines J, Simon SD, Dooren VV, Aktan G, Pritchard KI, Wolff AC, et al: Analysis of regional timelines to set up a global phase III clinical trial in breast cancer: The adjuvant lapatinib and/or trastuzumab treatment optimization experience. Oncologist 18: 134-140, 2013.
2. Bower JE, Greendale G, Crosswell AD, Garet D, Sternlieb B, Ganz PA, Irwin MR, Olmstead R, Arevalo J and Cole SW: Yoga reducesinflammatory signalinginfatigued breastcancersurvivors: A randomized controlled trial. Psychoneuroendocrinology 43: 20-29, 2014.

3. Pu Z, Zhang X, Chen Q, Yuan X and Xie H: Establishment of an expression platform of OATP1B1 388GG and 521CC genetic polymorphism and the therapeutic effect of tamoxifen in MCF-7 cells. Oncol Rep 33: 2420-2428, 2015.

4. Rodin D, Knaul FM, Lui TY and Gospodarowicz M: Radiotherapy for breast cancer: The predictable consequences of an unmet need. Breast 29: 120-122, 2016.

5. Fisher B, Anderson S, Bryant J, Margolese RG, Deutsch M, Fisher ER, Jeong JH and Wolmark N: Twenty-year follow-up of a randomized trial comparing total mastectomy, lumpectomy, and lumpectomy plus irradiation for the treatment of invasive breast cancer. N Engl J Med 347: 1233-1241, 2002.

6. Kim JJ and Tannock IF: Repopulation of cancer cells during therapy: An important cause of treatment failure. Nat Rev Cancer 5: 516-525, 2005.

7. Peitzsch C, Kurth I, Kunz-Schughart L, Baumann M and Dubrovska A: Discovery of the cancer stem cell related determinants of radioresistance. Radiother Oncol 108: 378-387, 2013.

8. Gerber DE: Targeted therapies: A new generation of cancer treatments. Am Fam Physician 77: 311-319, 2008.

9. Haraguchi H, Kataoka S, Okamoto S, Hanafi M and Shibata K: Antimicrobial triterpenes from Ilex integra and the mechanism of antifungal action. Phytother Res 13: 151-156, 1999.

10. Zhao WM, Wolfender JL, Hostettmann K, Cheng KF, Xu RS and Qin GW: Triterpenes and triterpenoid saponins from Mussaenda pubescens. Phytochemistry 45: 1073-1078, 1997.

11. Bhattacharyya J and de Almeida MZ: Isolation of the constituents of the root-bark of Guettarda platypoda. J Nat Prod 48: 148-149, 1985.

12. Saimaru H, Orihara Y, Tansakul P, Kang YH, Shibuya M and Ebizuka Y: Production of triterpene acids by cell suspension cultures of Olea europaea. Chem Pharm Bull (Tokyo) 55: 784-788, 2007.

13. Lee TH, Juang SH, Hsu FL and Wu CY: Triterpene acids from the leaves of Planchonella duclitan (Blanco) Bakhuizan. J Chin Chem Soc (Taipei) 52: 1275-1280, 2005.

14. Kim MH, Park KH, Oh MH, Kim HH, Choe KI, Park SH and Lee MW: Two new hemiterpene glycosides from the leaves of Ilex otunda. Thunb. Arch Pharm Res 35: 1779-84, 2012.

15. Lin FP, Shao JW, Du HD, Dai YC and Wang T: Synthesis, characterization and anti-tumor activity of ursolic acid derivatives. Chin J Appl Chem 27: 893-898, 2010 (In Chinese).

16. Darby S, McGale P, Correa C, Taylor C, Arriagada R, Clarke M, Cutter D, Davies C, Ewertz M, Godwin J, et al; Early Breast Cancer Trialists' Collaborative Group (EBCTCG): Effect of radiotherapy after breast-conserving surgery on 10-year recurrence and 15-year breast cancer death: Meta-analysis of individual patient data for 10,801 women in 17 randomised trials. Lancet 378: 1707-1716, 2011.

17. Darby SC, Ewertz M, McGale P, Bennet AM, Blom-Goldman U, Brønnum D, Correa C, Cutter D, Gagliardi G, Gigante B, et al: Risk of ischemic heart disease in women after radiotherapy for breast cancer. N Engl J Med 368: 987-998, 2013.

18. Hayes SB, Freedman GM, Li T, Anderson PR and Ross E: Does axillary boost increase lymphedema compared with supraclavicular radiation alone after breast conservation? Int J Radiat Oncol Biol Phys 72: 1449-1455, 2008.

19. Sandoo A, Kitas GD and Carmichael AR: Breast cancer therapy and cardiovascular risk: Focus on trastuzumab. Vasc Health Risk Manag 11: 223-228, 2015.

20. Lian L, Li W, Li ZY, Mao YX, Zhang YT, Zhao YM, Chen K, Duan WM and Tao M: Inhibition of MCF-7 breast cancer cellinduced platelet aggregation using a combination of antiplatelet drugs. Oncol Lett 5: 675-680, 2013.

21. Li W, Liang RR, Zhou C, Wu MY, Lian L, Yuan GF, Wang MY, Xie X, Shou LM, Gong FR, et al: The association between expressions of Ras and CD68 in the angiogenesis of breast cancers. Cancer Cell Int 15: 17, 2015.

22. Shou LM, Zhang QY, Li W, Xie X, Chen K, Lian L, Li ZY, Gong FR, Dai KS, Mao YX, et al: Cantharidin and norcantharidin inhibit the ability of MCF-7 cells to adhere to platelets via protein kinase $C$ pathway-dependent downregulation of $\alpha 2$ integrin. Oncol Rep 30: 1059-1066, 2013. 
23. Majeed W, Aslam B, Javed I, Khaliq T, Muhammad F, Ali A and Raza A: Breast cancer: Major risk factors and recent developments in treatment. Asian Pac J Cancer Prev 15: 3353-3358, 2014.

24. Lee CL, Blum JM and Kirsch DG: Role of p53 in regulating tissue response to radiation by mechanisms independent of apoptosis. Transl Cancer Res 2: 412-421, 2013.

25. Menon V and Povirk L: Involvement of p53 in the repair of DNA double strand breaks: Multifaceted roles of p53 in homologous recombination repair (HRR) and non-homologous end joining (NHEJ). Subcell Biochem 85: 321-336, 2014.

26. Hu D, Su C, Jiang M, Shen Y, Shi A, Zhao F, Chen R, Shen Z, Bao J and Tang W: Fenofibrate inhibited pancreatic cancer cells proliferation via activation of p53 mediated by upregulation of LncRNA MEG3. Biochem Biophys Res Commun 471: 290-295, 2016.

27. He YF, Nan ML, Sun JM, Meng ZJ, Yue FG, Zhao QC, Yang XH and Wang H: Synthesis, characterization and cytotoxicity of new rotundic acid derivatives. Molecules 17: 1278-1291, 2012.

28. Livak KJ and Schmittgen TD: Analysis of relative gene expression data using real-time quantitative PCR and the 2(-Delta Delta C(T)) Method. Methods 25: 402-408, 2001.

29. Kim GD, Choi YH, Dimtchev A, Jeong SJ, Dritschilo A and Jung M: Sensing of ionizing radiation-induced DNA damage by ATM through interaction with histone deacetylase. J Biol Chem 274: 31127-31130, 1999

30. Liu XY, Zhang FR, Shang JY, Liu YY, Lv XF, Yuan JN, Zhang TT, Li K, Lin XC, Liu X, et al: Renal inhibition of miR-181a ameliorates 5-fluorouracil-induced mesangial cell apoptosis and nephrotoxicity. Cell Death Dis 9: 610, 2018.

31. Zaki I, Abdelhameid MK, El-Deen IM, Abdel Wahab AHA, Ashmawy AM and Mohamed KO: Design, synthesis and screening of 1,2,4-triazinone derivatives as potential antitumor agents with apoptosis inducing activity on MCF-7 breast cancer cell line. Eur J Med Chem 156: 563-579, 2018.

32. Singh PK, Weber A and Häcker G: The established and the predicted roles of dynein light chain in the regulation of mitochondrial apoptosis. Cell Cycle 18: 1-11, 2018.

33. O'Brien KM, Sandler DP, Xu Z, Kinyamu HK, Taylor JA and Weinberg CR: Vitamin D, DNA methylation, and breast cancer. Breast Cancer Res 20: 70, 2018.

34. Mrózek E, Layman R, Ramaswamy B, Lustberg M, Vecchione A, Knopp MV and Shapiro CL: Phase II trial of neoadjuvant weekly nanoparticle albumin-bound paclitaxel, carboplatin, and biweekly bevacizumab therapy in women with clinical stage II or III HER2-negative breast cancer. Clin Breast Cancer 14 $228-234,2014$
35. Zuo S, Liu C, Wang J, Wang F, Xu W, Cui S, Yuan L, Chen X, Fan W, Cui M, et al: IGFBP-rP1 induces p21 expression through a p53-independent pathway, leading to cellular senescence of MCF-7 breast cancer cells. J Cancer Res Clin Oncol 138 1045-1055, 2012.

36. Shokouh TZ, Ezatollah A and Barand P: Interrelationships Between Ki67, HER2/neu, p53, ER, and PR status and their associations with tumor grade and lymph node involvement in breast carcinoma subtypes: Retrospective-observational analytical study. Medicine (Baltimore) 94: e1359, 2015.

37. Zhao QC, Nan ML, He YF and Chen SW: Application of rotundic Aacid in the cardiovascular disease prevention. CHN Patent 201010204596.9, 2010 (In Chinese).

38. Zhao QC, Nan ML, He YF and Chen SW: Application of rotundic acid in the preparation of lipid-lowering drugs. CHN 201010204607: 3, 2010 (In Chinese).

39. Cao W, Gu Y, Meineck M and Xu H: The combination of chemotherapy and radiotherapy towards more efficient drug delivery. Chem Asian J 9: 48-57, 2014

40. Li SJ, Liang XY, Li HJ, Yang GZ, Li W, Li Z, Zhou L, Wen X, $\mathrm{Yu}$ DH and Cui JW: Low-dose irradiation inhibits proliferation of the p53null type human prostate cancer cells through the ATM/p21 pathway. Int J Mol Med 41: 548-554, 2018.

41. Suzuki K, Okada H, Yamauchi M, Oka Y, Kodama S and Watanabe M: Qualitative and quantitative analysis of phosphorylated ATM foci induced by low-dose ionizing radiation. Radiat Res 165: 499-504, 2006.

42. Viniegra JG, Martínez N, Modirassari P, Hernández Losa J, Parada Cobo C, Sánchez-Arévalo Lobo VJ, Aceves Luquero CI, Alvarez-Vallina L, Ramón y Cajal S, Rojas JM, et al: Full activation of $\mathrm{PKB} / \mathrm{Akt}$ in response to insulin or ionizing radiation is mediated through ATM. J Biol Chem 280: 4029-4036, 2005.

43. Yin J, Wang F, Kong Y, Wu R, Zhang G, Wang N, Wang L, Lu Z and Liang M: Antithrombin III prevents progression of chronic kidney disease following experimental ischaemic-reperfusion injury. J Cell Mol Med 21: 3506-3514, 2017.

44. Lu Z, Cheng D, Yin J, Wu R, Zhang G, Zhao Q, Wang N, Wang F and Liang M: Antithrombin III protects against contrast-induced nephropathy. EBioMedicine 17: 101-107, 2017. 